\title{
Carbon monoxide oxidation on the Pt-catalyst: modelling and stability
}

\author{
Ryzha I., Matseliukh M. \\ Lviv Polytechnic National University \\ 12 S. Bandera str., 79013, Lviv, Ukraine
}

(Received 30 August 2017)

\begin{abstract}
A two-dimensional mathematical model of carbon monoxide $(\mathrm{CO})$ oxidation is investigated for the Langmuir-Hinshelwood mechanism on the surface of a Platinum (Pt) catalyst. The adsorbate-driven structural phase transition of catalytic surface is taken into account. The stability analysis of the model solutions is carried out. It is shown that the spatio-temporal periodic chemical oscillations of $\mathrm{CO}$ and oxygen $(\mathrm{O})$ surface coverages and a fraction of the surface in the non-reconstructed $(1 \times 1)$-structure occur. Conditions for Hopf and Turing bifurcation to arise are investigated.
\end{abstract}

Keywords: reaction of catalytic oxidation, reaction-diffusion model, Hopf bifurcation, Turing bifurcation.

2000 MSC: 37E99, 82D99, 82C21

UDC: 538.9

\section{Introduction}

Spatio-temporal patterns arising from the complex interplay of the components of non-equilibrium nonlinear systems are typical for many natural phenomena [1]. To gain a deeper understanding of these systems researchers sought simpler laboratory systems that would allow one to study in detail the mechanisms of spatio-temporal structures formation $[2,3]$. One of these model systems is the reaction of catalytic carbon monoxide $(\mathrm{CO})$ oxidation on $\mathrm{Pt}(110)$ crystal surface [4]. This heterogeneous reaction demonstrates various concepts in nonlinear dynamics ranging from the basic pattern formation mechanisms [5] to chaos control with the global [6] and local [7] feedback.

The kinetics of carbon monoxide oxidation processes on a platinum $(\mathrm{Pt})$ surface was studied in a large number of works [8]. However, the experimental studies on the level of nanocatalytic processes remain actual as well as theoretical ones, since the theoretical description of these nanocatalytic processes is not yet sufficiently developed.

Obviously, it is impossible to build a model for a quantitative description of carbon monoxide catalytic oxidation without understanding the mechanisms of this process. One of the mechanisms of catalytic CO oxidation on the platinum catalyst surface is the Langmuir-Hinshelwood (LH) mechanism, studied by Baxter and others [9].

In the $(\mathrm{LH})$ mechanism the two reacting species $\mathrm{CO}$ and oxygen $(\mathrm{O})$ have to adsorb on the catalytic surface (onto places called active adsorption sites) before the reaction takes place. Then adsorbed $\mathrm{CO}_{a d s}$ and $\mathrm{O}_{a d s}$ (subscript 'ads' denotes an adsorbed state) react under thermodynamically favourable conditions. The product of reaction, carbon dioxide $\left(\mathrm{CO}_{2}\right)$, desorbs from the catalytic surface immediately.

Chemical reactions that may proceed during CO oxidation on the catalytic surface via (LH) mechanism are described with the following chemical equations:

$$
\begin{aligned}
\mathrm{O}_{2}+2 * & \rightarrow 2 \mathrm{O}_{a d s}, \\
\mathrm{CO}+* & \leftrightarrow \mathrm{CO}_{a d s}, \\
\mathrm{CO}_{a d s}+\mathrm{O}_{a d s} & \rightarrow \mathrm{CO}_{2}+2 *,
\end{aligned}
$$

where ' $*$ ' denotes an empty adsorption site on the catalytic surface. 
When modelling the reaction of $\mathrm{CO}$ oxidation within chemical kinetics equations we assume that reaction takes place only on the catalyst surface. That is, the interactions can occur only between particles adsorbed on the catalyst surface. In order for oxygen to absorb a molecule breaks up into two atoms near the catalyst surface, and then each atom absorbs onto distinct empty site independently [10]. The CO molecules adsorb onto surface and stay on it without breaking up into atoms. The transformation of particles is possible only in the adsorbed layer. During adsorption the $\mathrm{O}_{2}$ molecules rapidly dissociate into atoms. Oxygen desorption is very unlikely to occur in the range of temperatures at which experiments are conducted and, therefore, desorption is neglected. Since diffusion coefficient of adsorbed oxygen is 3-4 orders of magnitude smaller than CO diffusion coefficient [11], adsorbed oxygen is considered to be immobile.

The processes of surface reconstruction of the catalyst atoms play a crucial role in heterogeneous catalysis. The clean $\mathrm{Pt}(110)$ surface is reconstructed and has a $(1 \times 2)$-structure [12]. During reaction oxygen and $\mathrm{CO}$ adsorb on the $\mathrm{Pt}$ surface. If $\mathrm{CO}$ coverage exceeds specific critical value the surface reconstructs into $(1 \times 1)$ bulk structure [13]. When oxygen and CO react, carbon dioxide is formed, and surface returns to its initial configuration. Such structural changes influence the rates of other elementary processes, therefore, should be taken into account when developing a mathematical model of reaction.

This work is devoted to investigation of formation and stability of the surface spatio-temporal structures arising in reaction-diffusion model of $\mathrm{CO}$ oxidation on a $\mathrm{Pt}(110)$ surface when two dimensions are taken into account. The analysis of spatio-temporal instabilities is conducted by using methods of linear stability theory and numerical simulation.

\section{Description of mathematical model}

We consider a model for catalytic $\mathrm{CO}$ oxidation that accounts for diffusion of molecules of $\mathrm{CO}$ on $\mathrm{Pt}(110)$ surface. Assume that catalytic surface is flat with a given Cartesian coordinate system XOY. The time evolution of $\mathrm{CO}$ and $\mathrm{O}$ coverages on the catalyst surface is determined by the following kinetic equations $[14,15]$ :

$$
\begin{aligned}
& \frac{\partial u}{\partial t}=\overbrace{p_{u} \kappa_{u} s_{u}\left(1-\left(u / u_{s a t}\right)^{q}\right)}^{\text {adsorption }}-\overbrace{k_{d e s} u}^{\text {desorption }}-\overbrace{k_{r} u v}^{\text {adsorption }}+\overbrace{D_{x} \frac{\partial^{2} u}{\partial x^{2}}+D_{y} \frac{\partial^{2} u}{\partial y^{2}}}^{\text {diffusion }} \\
& \frac{\partial v}{\partial t}=\overbrace{p_{v} \kappa_{v} s_{v}\left(1-u / u_{\text {sat }}-v / v_{\text {sat }}\right)^{2}}^{\text {reaction }}-\overbrace{k_{r} u v}^{\text {reaction }},
\end{aligned}
$$

Here $u$ and $v$ denote $\mathrm{CO}$ and $\mathrm{O}$ surface coverages, respectively; $p_{u}, p_{v}$ are the partial pressures of species; $\kappa_{u}, \kappa_{v}$ are the impingement rates; $s_{u}, s_{v}$ are the sticking coefficients; $u_{\text {sat }}, v_{\text {sat }}$ refer to the maximal coverages namely the saturation coverages; $k_{r}, k_{d e s}$ are the rates of reaction and CO desorption; $D_{x}, D_{y}$ are CO diffusion coefficients in $x$ and $y$ directions, respectively. The factor $q=3$ models the precursor-type kinetics [16] of $\mathrm{CO}$ adsorption since the inhibition of $\mathrm{CO}$ and $\mathrm{O}_{2}$ adsorption is asymmetric and adsorbed $\mathrm{CO}$ blocks oxygen adsorption stronger.

The structural phase transition on $\operatorname{Pt}(110)$ surface is modelled by the following law [17,18]:

$$
\frac{\partial W}{\partial t}=\overbrace{k_{p h}(f(u)-W)}^{\text {reconstruction }},
$$

where variable $W$ denotes the fraction of surface in the nonreconstructed structure (surface of type $(1 \times 1))$, coefficient $k_{p h}$ is a rate of structural phase transition and

$$
f(u)=\frac{1}{1+\exp \left(\frac{u_{0}-\frac{u}{u_{s a t}}}{\delta u}\right)}
$$


is a nondecreasing smooth function of the interval $[0,1]$. Parameter $u_{0}$ determines the threshold value above which adsorbed CO molecules significantly influence the structure of the surface, and $\delta u$ determines the steepness of this threshold.

The sticking coefficient $s_{v}$ is modified in equation (3) and can be rewritten as a linear combination of values for the $(1 \times 1)$ and $(1 \times 2)$ structures:

$$
s_{v}=s_{v}^{1 \times 1} W+s_{v}^{1 \times 2}(1-W),
$$

where $s_{v}^{1 \times 1}, s_{v}^{1 \times 2}$ are the oxygen sticking coefficients in $(1 \times 1)$ and $(1 \times 2)$ phases, respectively.

The rates of reaction, desorption and phase transition are temperature dependent and are determined by the Arrhenius equations [19]:

$$
\begin{aligned}
k_{r}[T] & =k_{r}^{0} \exp \left(-E_{r} / R T\right), \\
k_{d e s}[T] & =k_{d e s}^{0} \exp \left(-E_{\text {des }} / R T\right), \\
k_{p h}[T] & =k_{p h}^{0} \exp \left(-E_{p h} / R T\right) .
\end{aligned}
$$

Here $k_{r}^{0}, k_{d e s}^{0}, k_{p h}^{0}$ are temperature-independent coefficients; $E_{r}, E_{d e s}, E_{p h}$ are the activation energies; $R$ is the universal gas constant.

Equations (2)-(4) compose a mathematical model of carbon monoxide catalytic oxidation process.

\section{Stability analysis of a system}

Equations (2)-(4) are transformed into dimensionless form by substituting:

$$
\begin{gathered}
u=u_{\text {sat }} U, \quad v=v_{\text {sat }} V, \\
x=l_{0} \tilde{x}, \quad y=l_{0} \tilde{y}, \quad t=t_{c} \tilde{t},
\end{gathered}
$$

where

$$
t_{c}=v_{s a t} / p_{u} \kappa_{u} s_{u} .
$$

Parameter $l_{0}$ is chosen according to experimental data for the size of Pt-crystal $l_{0} \sim 10^{-3} \mathrm{sm}[20]$.

In dimensionless form equations (2)-(4) compose a mathematical model of catalytic CO oxidation on the Pt surface:

$$
\left\{\begin{aligned}
\frac{\partial U}{\partial \tilde{t}} & =\frac{v_{\text {sat }}}{u_{\text {sat }}}\left(1-U^{q}\right)-\tilde{k}_{\text {des }} U-\tilde{k}_{r} v_{\text {sat }} U V+\tilde{D}_{x}\left(\frac{\partial^{2} U}{\partial \tilde{x}^{2}}+D_{0} \frac{\partial^{2} U}{\partial \tilde{y}^{2}}\right) \equiv \\
& \equiv F(U, V)+\tilde{D}_{x}\left(\frac{\partial^{2} U}{\partial \tilde{x}^{2}}+D_{0} \frac{\partial^{2} U}{\partial \tilde{y}^{2}}\right) \\
\frac{\partial V}{\partial \tilde{t}} & =\tilde{p}_{v}\left[s_{v}^{1 \times 1} W+s_{v}^{1 \times 2}(1-W)\right](1-U-V)^{2}-\tilde{k}_{r} u_{s a t} U V \equiv G(U, V, W), \\
\frac{\partial W}{\partial \tilde{t}} & =\tilde{k}_{p h}\left\{\left[1+\exp \left(\frac{u_{0}-U}{\delta u}\right)\right]^{-1}-W\right\} \equiv H(U, W) .
\end{aligned}\right.
$$

In system (13):

$$
\begin{aligned}
& \tilde{k}_{\text {des }}=k_{\text {des }} t_{c}, \quad \tilde{k}_{r}=k_{r} t_{c}, \quad \tilde{k}_{p h}=k_{p h} t_{c} \\
& \tilde{p}_{v}=\frac{p_{v} \kappa_{v} t_{c}}{v_{s a t}}, \quad \tilde{D}_{x}=\frac{D_{x} t_{c}}{l_{0}^{2}}, \quad D_{0}=\frac{D_{y}}{D_{x}} .
\end{aligned}
$$

Explanation and parameter values used in numerical calculations are given in Tabl. 1 [14,18]. The partial pressures $p_{u}$ and $p_{v}$ and the temperature $T$ play a role of control parameters of a model. 
Table 1. Parameters of mathematical model.

\begin{tabular}{|c|c|c|l|}
\hline $\mathrm{CO}$ & Partial pressure & $p_{u}$ & \\
& Impingement rate & $\kappa_{u}$ & $4.2 \times 10^{5} 1 / \mathrm{s}$ Torr \\
& Sticking coefficient & $s_{u}$ & 1 \\
$\mathrm{O}_{2}$ & Saturation coverage & $u_{\text {sat }}$ & 1 \\
& Diffusion coefficient & $D_{x}$ & $1.2 \times 10^{-7} \mathrm{sm}^{2} / \mathrm{s}$ \\
& Partial pressure & $p_{v}$ & \\
& Impingement rate & $\kappa_{v}$ & $7.8 \times 10^{5} 1 / \mathrm{s} \mathrm{Torr}$ \\
& Sticking coefficient & $s_{v}^{1 \times 1} ; s_{v}^{1 \times 2}$ & 0,$6 ; 0,4$ \\
& Saturation coverage & $v_{s a t}$ & 0.8 \\
& Reaction & $k_{r}^{0}$ & $3 \times 10^{6} 1 / \mathrm{s}$ \\
& & $E_{r}$ & $10 \mathrm{kcal} / \mathrm{mol}$ \\
& Desorption of CO & $k_{d e s}^{0}$ & $2 \times 10^{16} 1 / \mathrm{s}$ \\
& Phase transition & $E_{d e s}$ & $38 \mathrm{kcal} / \mathrm{mol}$ \\
& & $k_{p h}^{0}$ & $2 \times 10^{-2} 1 / \mathrm{s}$ \\
& Temperature & $E_{p h}$ & $7 \mathrm{kcal} / \mathrm{mol}$ \\
& Gas constant & $T$ & \\
& Model parameter of diffusion & $R$ & $0.001987 \mathrm{kcal} / \mathrm{mol} \mathrm{K}$ \\
& Parameters of structural phase transition & $n_{0} ; \delta u$ & $0.35 ; 0.05$ \\
\hline
\end{tabular}

System (13) is a system of three nonlinear partial differential equations. It can have spatiohomogeneous steady-state solutions $\left(U^{s}, V^{s}, W^{s}\right)$ satisfying the system of algebraic equations:

$$
F\left(U^{s}, V^{s}\right)=0, \quad G\left(U^{s}, V^{s}, W^{s}\right)=0, \quad H\left(U^{s}, W^{s}\right)=0 .
$$

The number of real solutions of system (14) classifies it as mono or multistable.

We analyze the stability of homogeneous steady-state solutions of system (13). To do this we first consider the corresponding system of kinetic equations when diffusion is absent. That is, the system of the form:

$$
\left\{\begin{array}{l}
\frac{\partial U}{\partial \tilde{t}}=F(U, V), \\
\frac{\partial V}{\partial \tilde{t}}=G(U, V, W), \\
\frac{\partial W}{\partial \tilde{t}}=H(U, W) .
\end{array}\right.
$$

We introduce small deviations from the steady states $\left(U^{s}, V^{s}, W^{s}\right)$ :

$$
U=U^{s}+\delta U(\tilde{t}), \quad V=V^{s}+\delta V(\tilde{t}), \quad W=W^{s}+\delta W(\tilde{t}),
$$

where $\delta U(\tilde{t}), \delta V(\tilde{t}), \delta W(\tilde{t})$ are time-dependent small perturbations. The linearised system (15) near $\left(U^{s}, V^{s}, W^{s}\right)$ looks as follows:

$$
\frac{d}{d \tilde{t}}\left(\begin{array}{lll}
\delta U & \delta V & \delta W
\end{array}\right)^{\top}=\boldsymbol{M} \cdot\left(\begin{array}{lll}
\delta U & \delta V & \delta W
\end{array}\right)^{\top}
$$

where

$$
\boldsymbol{M}=\left(\begin{array}{ccc}
F_{U}^{\prime} & F_{V}^{\prime} & 0 \\
G_{U}^{\prime} & G_{V}^{\prime} & G_{W}^{\prime} \\
H_{U}^{\prime} & 0 & H_{W}^{\prime}
\end{array}\right)_{\left(U^{s}, V^{s}, W^{s}\right)}
$$

is the Jacobian matrix [21] for the system of functions (15), where all partial derivatives are calculated at a stationary point $\left(U^{s}, V^{s}, W^{s}\right)$. 
We look for solutions $(\delta U, \delta V, \delta W)$ of the system (16) which are proportional to $e^{\lambda \tilde{t}}$, where $\lambda$ are the eigenvalues of a matrix (17). The calculation of eigenvalues $\lambda$ reduces to solving the following cubic equation:

$$
\lambda^{3}-\lambda^{2} \operatorname{tr} \boldsymbol{M}+\lambda\left(F_{U}^{\prime} G_{V}^{\prime}+F_{U}^{\prime} H_{W}^{\prime}+G_{V}^{\prime} H_{W}^{\prime}-F_{V}^{\prime} G_{U}^{\prime}\right)-\operatorname{det} \boldsymbol{M}=0,
$$

where $\operatorname{tr} \boldsymbol{M}$ and $\operatorname{det} \boldsymbol{M}$ are the trace and the determinant of matrix $\boldsymbol{M}$, respectively.

Solutions $\left(U^{s}, V^{s}, W^{s}\right)$ are stable when $\operatorname{Re}\left(\lambda_{i}\right)<0, i=1,2,3$. According to the Routh-Hurwitz criterion [21] the necessary and sufficient conditions for this are:

$$
\left\{\begin{array}{l}
\operatorname{tr} \boldsymbol{M}<0, \\
\operatorname{det} \boldsymbol{M}<0, \\
F_{V}^{\prime} G_{U}^{\prime}<F_{U}^{\prime} G_{V}^{\prime}+F_{U}^{\prime} H_{W}^{\prime}+G_{V}^{\prime} H_{W}^{\prime}, \\
\operatorname{det} \boldsymbol{M}>\operatorname{tr} \boldsymbol{M}\left(F_{U}^{\prime} G_{V}^{\prime}+F_{U}^{\prime} H_{W}^{\prime}+G_{V}^{\prime} H_{W}^{\prime}-F_{V}^{\prime} G_{U}^{\prime}\right) .
\end{array}\right.
$$

If any of these conditions is violated the homogeneous steady-state solutions are unstable.

Conditions (19) determine the stability region of a system in the $\left(p_{v}, p_{u}\right)$-parameter plane (see Fig. 1-2).

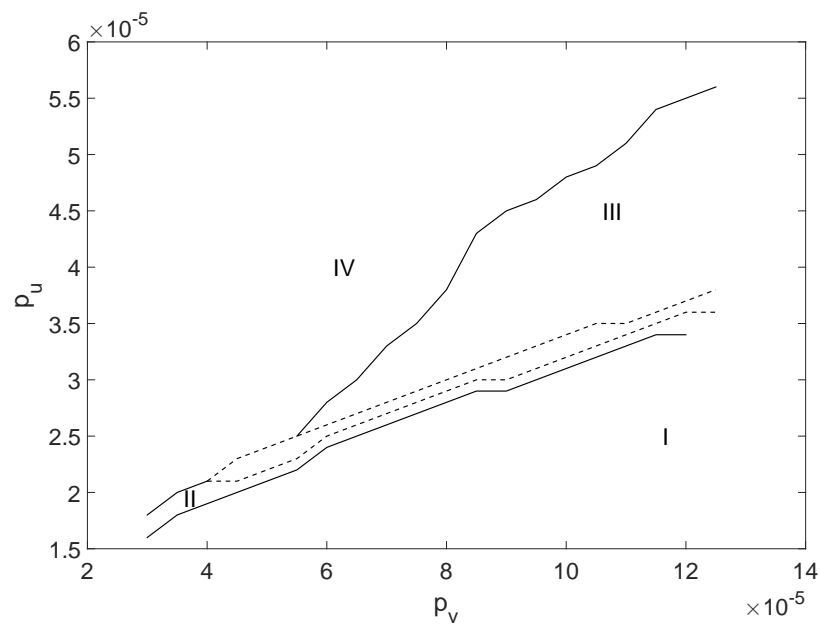

Fig. 1. Stability diagram of the system (13) in the pressure plane $\left(p_{v}, p_{u}\right)$ for the temperature $T=540 \mathrm{~K}$.

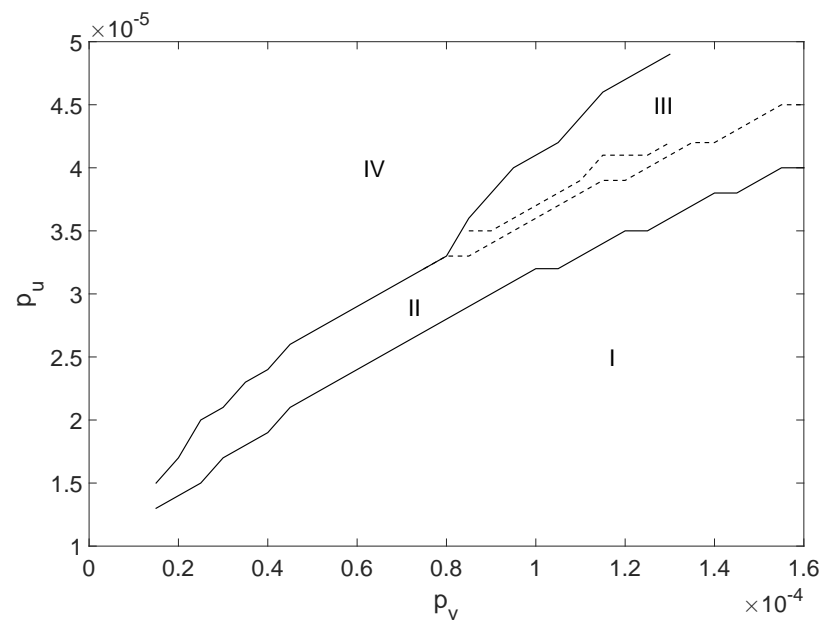

Fig. 2. Stability diagram of the system in the pressure plane $\left(p_{v}, p_{u}\right)$ without taking temperature dependence into account.

Fig. 1-2 show that there are four regions in the pressure plane $\left(p_{v}, p_{u}\right)$. In regions labeled I, II and IV the system is stable. In regions I and IV the deviations from equilibrium decrease exponentially. In region II the damped oscillations are observed. Region I is a region of high catalytic activity. There are adsorbed $\mathrm{CO}$ and $\mathrm{O}$ on the catalyst surface so the oxidation reaction occurs with high probability.Conversely, region IV is characterized by low catalytic activity since the catalyst surface is mostly covered by adsorbed CO. Under such conditions there is a low probability that oxidation reaction occurs. When leaving these regions one or more perturbations become unstable and the system leaves its initial steady-state. On the stability diagram this region is labeled III.

Fig. 2 shows that taking into account that rates of reaction, desorption and phase transition are dependent on temperature $T$ changes the stability region of the system, namely, narrows considerably the region II where the damped oscillations are observed.

Oscillations of $\mathrm{CO}$ and $\mathrm{O}$ surface coverages and the fraction of surface in the nonreconstructed $(1 \times 1)$-structure as well as the corresponding phase diagram of the system are depicted in Fig. 3-5. 

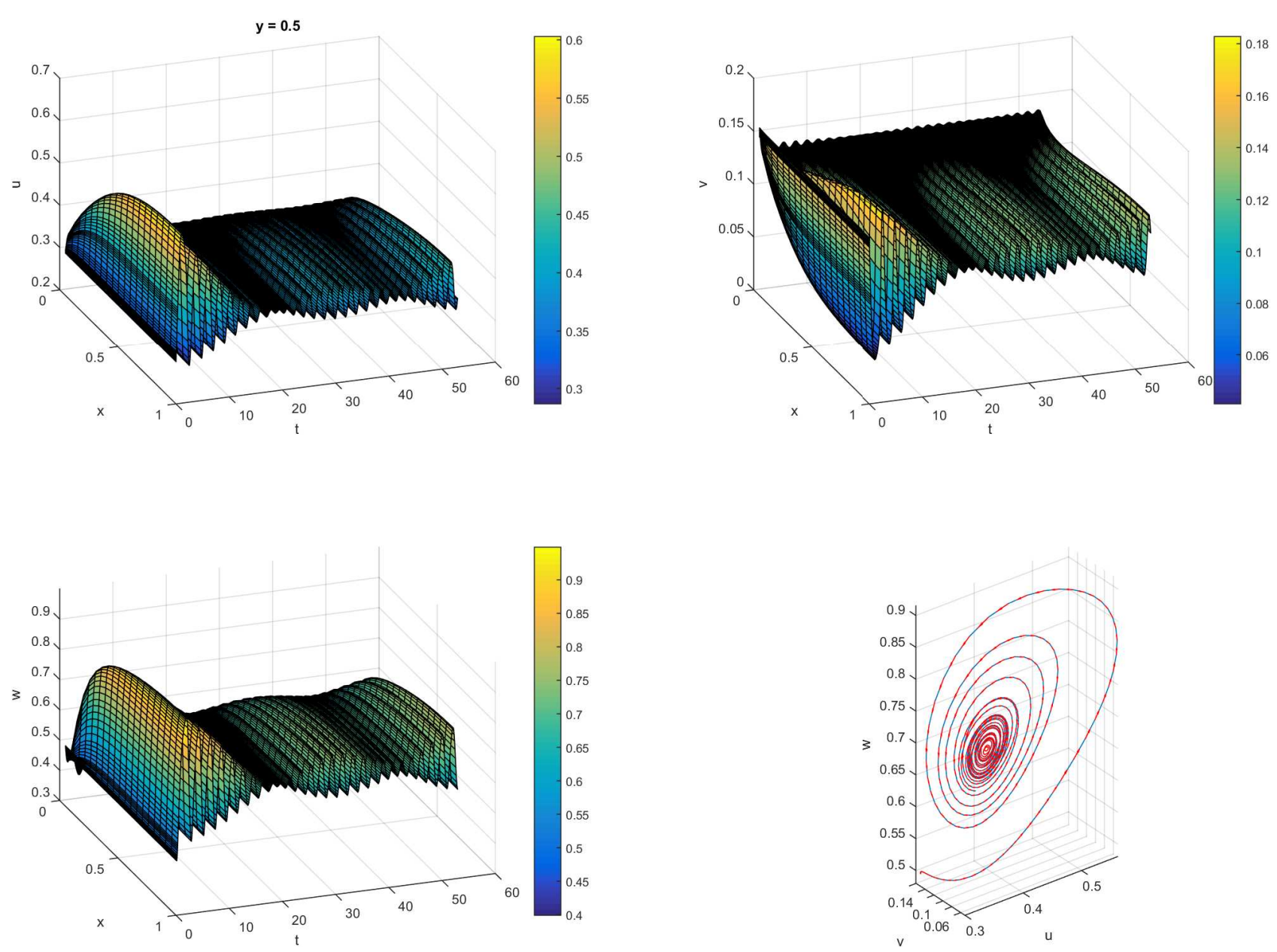

Fig. 3. Oscillations of $\mathrm{CO}$ and $\mathrm{O}$ surface coverages and the fraction of surface in the nonreconstructed $(1 \times 1)$ structure without taking temperature-dependence into account for partial pressures $p_{u}=3.6 \times 10^{-5}$ Torr, $p_{v}=$ $10.0 \times 10^{-5}$ Torr and a certain value of $y$-coordinate: $\tilde{y}=0.5$.

We consider the possibility for the Hopf bifurcation [22] to appear in model (13). It is a local dynamic instability which causes the stationary point to loose stability, and a limit cycle (the autooscillations) arises in the system. In this case all eigenvalues of the Jacobian matrix of the linearized system have negative real parts except for a pair of imaginary conjugate nonzero eigenvalues.

In our case the necessary and sufficient conditions for the Hopf bifurcation to occur are as follows:

$$
\left\{\begin{aligned}
\operatorname{tr} \boldsymbol{M} & <0, \\
\operatorname{det} \boldsymbol{M} & <0, \\
\operatorname{det} \boldsymbol{M} & =\operatorname{tr} \boldsymbol{M}\left(F_{U}^{\prime} G_{V}^{\prime}+F_{U}^{\prime} H_{W}^{\prime}+G_{V}^{\prime} H_{W}^{\prime}-F_{V}^{\prime} G_{U}^{\prime}\right) .
\end{aligned}\right.
$$

The auto-oscillations of $\mathrm{CO}$ and $\mathrm{O}$ surface coverages and the fraction of surface in the nonreconstructed $(1 \times 1)$-structure as well as the corresponding phase diagram of the system are shown in Fig. 6 . It can be seen that the phase trajectory spirals into the closed curve - the limit cycle. The average coverage of adsorbates and the fraction of $(1 \times 1)$-surface undergo periodic oscillations resulting from the Hopf bifurcation [23]. Such type of instability generates time-periodic patterns, i.e. waves. On the stability diagram of a system (see Fig. 1-2) the region where periodic chemical oscillations are observed is indicated by the dashed lines.

Now we consider the question about stability of model (13) when the diffusion processes are taken into account. The stability of homogeneous steady-state solutions of (14) can be analyzed by using a 

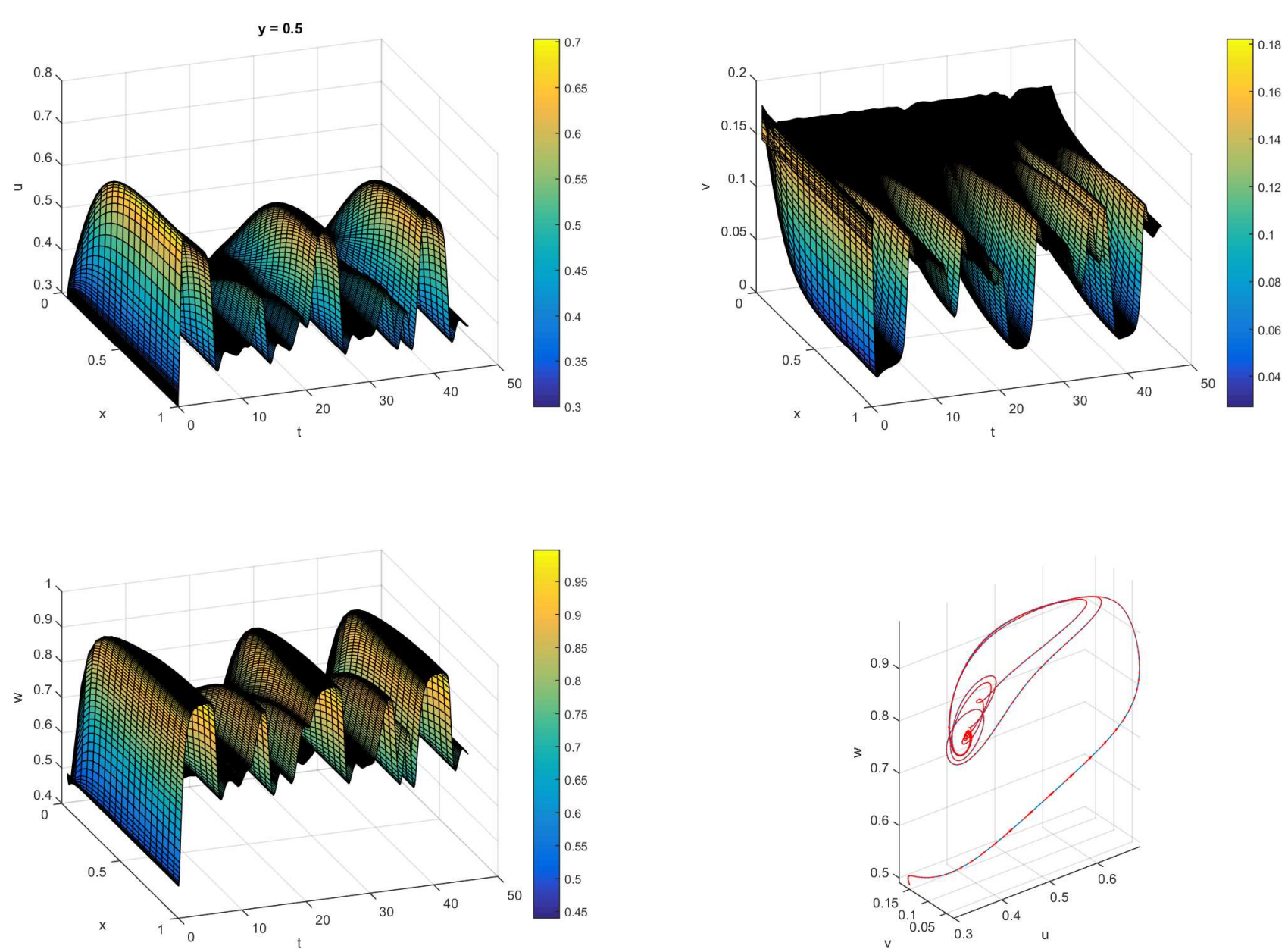

Fig. 4. Oscillations of $\mathrm{CO}$ and $\mathrm{O}$ surface coverages and the fraction of surface in the nonreconstructed $(1 \times 1)$ structure without taking temperature-dependence into account for partial pressures $p_{u}=4.2 \times 10^{-5}$ Torr, $p_{v}=$ $13.5 \times 10^{-5}$ Torr and a certain value of $y$-coordinate: $\tilde{y}=0.5$.

linearized system. We introduce small deviations from the steady states $\left(U^{s}, V^{s}, W^{s}\right)$ :

$$
U=U^{s}+\delta U(\tilde{x}, \tilde{y}, \tilde{t}), \quad V=V^{s}+\delta V(\tilde{x}, \tilde{y}, \tilde{t}), \quad W=W^{s}+\delta W(\tilde{x}, \tilde{y}, \tilde{t}),
$$

where $\delta U(\tilde{x}, \tilde{y}, \tilde{t}), \delta V(\tilde{x}, \tilde{y}, \tilde{t}), \delta W(\tilde{x}, \tilde{y}, \tilde{t})$ are small perturbations dependent on coordinates and time. The linearised system $(13)$ near $\left(U^{s}, V^{s}, W^{s}\right)$ looks as follows:

$$
\frac{\partial}{\partial \tilde{t}}\left(\begin{array}{lll}
\delta U & \delta V & \delta W
\end{array}\right)^{\top}=\boldsymbol{M} \cdot\left(\begin{array}{lll}
\delta U & \delta V & \delta W
\end{array}\right)^{\top}+\tilde{D}_{x}\left(\frac{\partial^{2}}{\partial \tilde{x}^{2}}+D_{0} \frac{\partial^{2}}{\partial \tilde{y}^{2}}\right)\left(\begin{array}{lll}
\delta U & 0 & 0
\end{array}\right)^{\top},
$$

where $\boldsymbol{M}$ is the Jacobian matrix determined by (17). We look for solutions $(\delta U, \delta V, \delta W)$ which are proportional to $e^{\lambda \tilde{t}+i\left(k_{1} \tilde{x}+k_{2} \tilde{y}\right)}$, where $\lambda$ are the eigenvalues for the temporal growth and $\boldsymbol{k}=\left(k_{1} ; k_{2}\right)$ are wavenumbers (the spatial eigenvalues).

Then the problem of stability analysis reduces to solving the following equation:

$$
\operatorname{det}\left(\begin{array}{ccc}
F_{U}^{\prime}-\lambda-\tilde{D}_{x}\left(k_{1}^{2}+D_{0} k_{2}^{2}\right) & F_{V}^{\prime} & 0 \\
G_{U}^{\prime} & G_{V}^{\prime}-\lambda & G_{W}^{\prime} \\
H_{U}^{\prime} & 0 & H_{W}^{\prime}-\lambda
\end{array}\right)_{\left(U^{s}, V^{s}, W^{s}\right)}=0
$$

where all partial derivatives are calculated at a stationary point $\left(U^{s}, V^{s}, W^{s}\right)$. To find the eigenvalues $\lambda, k_{1}, k_{2}$ we obtain from $(22)$ : 

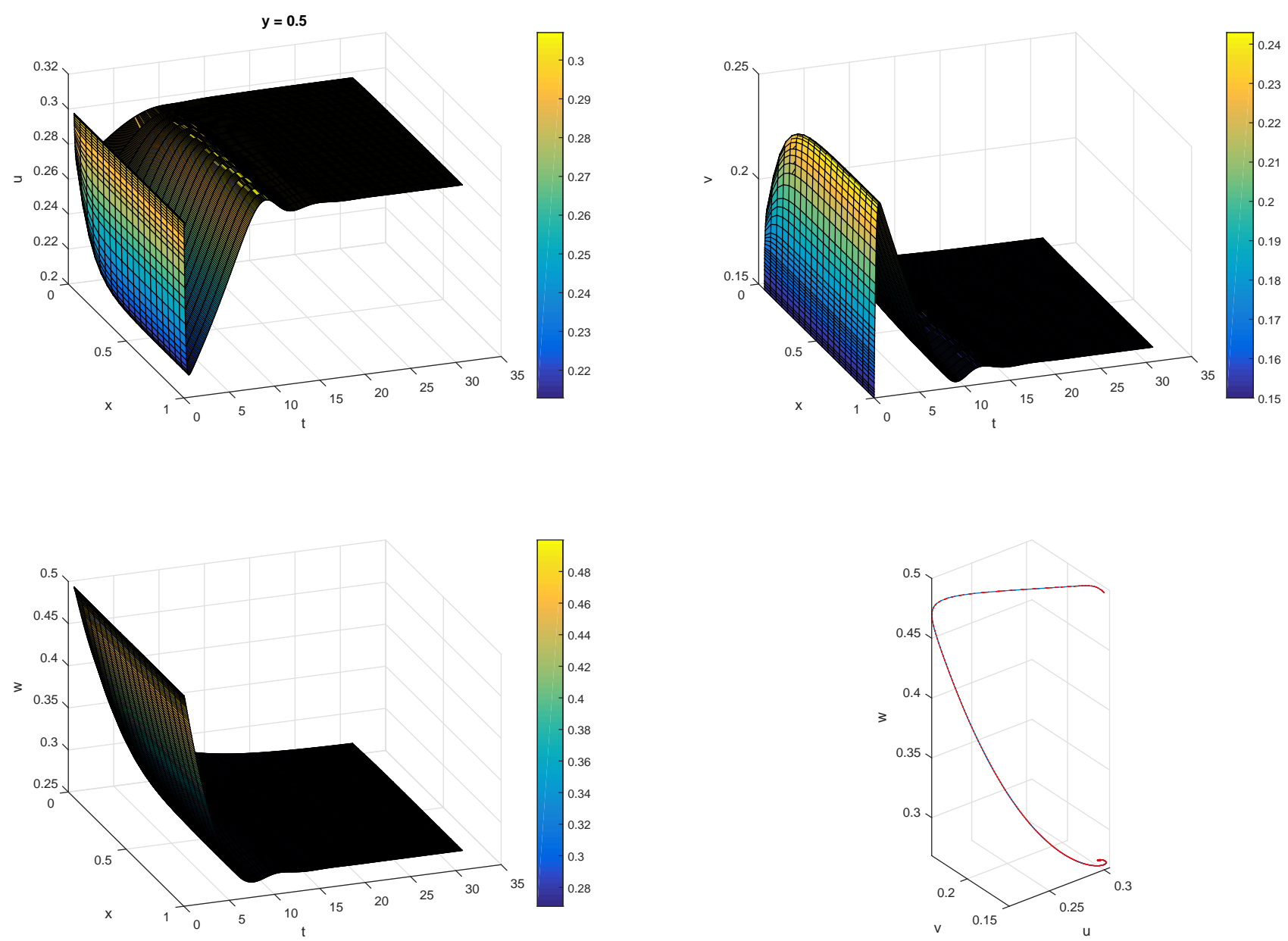

Fig. 5. Damped oscillations of $\mathrm{CO}$ and $\mathrm{O}$ surface coverages and the fraction of surface in the nonreconstructed $(1 \times 1)$-structure for a temperature $T=540 \mathrm{~K}$, partial pressures $p_{u}=3.1 \times 10^{-5}$ Torr, $p_{v}=9.75 \times 10^{-5}$ Torr and a certain value of $y$-coordinate: $\tilde{y}=0.5$.

$$
\begin{aligned}
& \lambda^{3}+\lambda^{2}\left(\tilde{D}_{x}\left(k_{1}^{2}+D_{0} k_{2}^{2}\right)-\operatorname{tr} \boldsymbol{M}\right) \\
& +\lambda\left(F_{U}^{\prime} G_{V}^{\prime}+F_{U}^{\prime} H_{W}^{\prime}+G_{V}^{\prime} H_{W}^{\prime}-F_{V}^{\prime} G_{U}^{\prime}-\tilde{D}_{x}\left(k_{1}^{2}+D_{0} k_{2}^{2}\right)\left(G_{V}^{\prime}+H_{W}^{\prime}\right)\right) \\
& +\tilde{D}_{x}\left(k_{1}^{2}+D_{0} k_{2}^{2}\right) G_{V}^{\prime} H_{W}^{\prime}-\operatorname{det} \boldsymbol{M}=0 .
\end{aligned}
$$

We investigate the necessary and sufficient conditions for the Turing bifurcation [24], an instability caused by diffusion processes, to arise. Note that we need a stable steady state in case when there are no spatial effects, i.e. $\operatorname{Re} \lambda(\boldsymbol{k})<0$ when $k_{1}, k_{2}=0$, which corresponds to conditions (19) found above. Second, we require $\operatorname{Re} \lambda(\boldsymbol{k})>0$ when $k_{1}, k_{2} \neq 0$, i.e. such that the steady state is unstable if the spatial disturbances (e.g. the diffusion) are present.

Let us find necessary and sufficient conditions for the cubic equation (23) to have at least one positive root. We estimate an upper bound on the number of positive real roots of equation (23) when $k_{1}, k_{2} \neq 0$ by using Descartes' rule of signs [21] and obtain:

$$
\begin{aligned}
& a_{0}=1>0 \\
& a_{1}=\tilde{D}_{x}\left(k_{1}^{2}+D_{0} k_{2}^{2}\right)-\operatorname{tr} \boldsymbol{M} \\
& a_{2}=F_{U}^{\prime} G_{V}^{\prime}+F_{U}^{\prime} H_{W}^{\prime}+G_{V}^{\prime} H_{W}^{\prime}-F_{V}^{\prime} G_{U}^{\prime}-\tilde{D}_{x}\left(k_{1}^{2}+D_{0} k_{2}^{2}\right)\left(G_{V}^{\prime}+H_{W}^{\prime}\right), \\
& a_{3}=\tilde{D}_{x}\left(k_{1}^{2}+D_{0} k_{2}^{2}\right) G_{V}^{\prime} H_{W}^{\prime}-\operatorname{det} \boldsymbol{M} .
\end{aligned}
$$



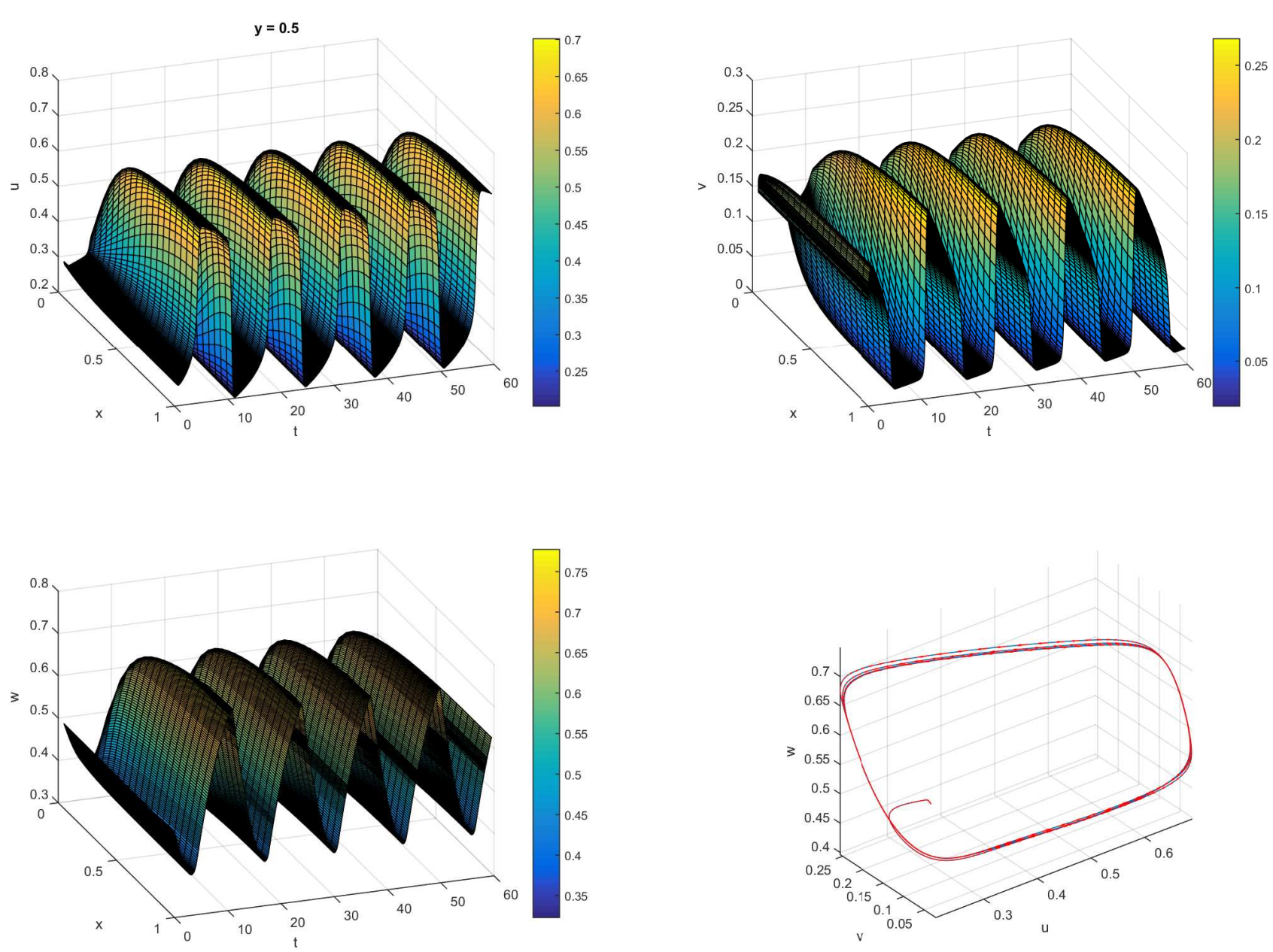

Fig. 6. Auto-oscillations of $\mathrm{CO}$ and $\mathrm{O}$ surface coverages and the fraction of surface in the nonreconstructed $(1 \times 1)$-structure for a temperature $T=540 \mathrm{~K}$, partial pressures $p_{u}=3.2 \times 10^{-5}$ Torr, $p_{v}=9.75 \times 10^{-5}$ Torr and a certain value of $y$-coordinate: $\tilde{y}=0.5$.

Taking into account conditions (19) on the trace and the determinant of matrix $\boldsymbol{M}$ (for the case without diffusion), and that the partial derivatives for the given model parameters are:

$$
G_{V}^{\prime}=-2 \tilde{p}_{v}\left[s_{v}^{1 \times 1} W+s_{v}^{1 \times 2}(1-W)\right](1-U-V)-\tilde{k}_{r} u_{s a t} U<0, \quad H_{W}^{\prime}=-\tilde{k}_{p h}<0,
$$

we find that there are no sign changes in the sequence of coefficients $\left(a_{i}, i=\overline{0,3}\right)$ when $k_{1}, k_{2} \neq 0$. Therefore the equation (23) has no positive roots.

However, it is possible that the roots of a polynomial are a pair of conjugate complex numbers with a positive real part. Then the steady state is unstable. Let us verify the necessary and sufficient conditions that all roots of a polynomial have negative real parts by using the Routh-Hurwitz criterion. At least one root of a polynomial (23) has a positive real part if and only if at least one of its Hurwitz determinants [21] is non-positive. In our case:

$$
\begin{aligned}
\Delta_{0}= & a_{0}=1, \\
\Delta_{1}= & a_{1}=\tilde{D}_{x}\left(k_{1}^{2}+D_{0} k_{2}^{2}\right)-\operatorname{tr} \boldsymbol{M}, \\
\Delta_{2}= & -\tilde{D}_{x}^{2}\left(k_{1}^{2}+D_{0} k_{2}^{2}\right)^{2}\left(G_{V}^{\prime}+H_{W}^{\prime}\right) \\
& +\tilde{D}_{x}\left(k_{1}^{2}+D_{0} k_{2}^{2}\right)\left[2 F_{U}^{\prime} G_{V}^{\prime}+2 F_{U}^{\prime} H_{W}^{\prime}+2 G_{V}^{\prime} H_{W}^{\prime}-F_{V}^{\prime} G_{U}^{\prime}+\left(G_{V}^{\prime}\right)^{2}+\left(H_{W}^{\prime}\right)^{2}\right] \\
& -\operatorname{tr} \boldsymbol{M}\left(F_{U}^{\prime} G_{V}^{\prime}+F_{U}^{\prime} H_{W}^{\prime}+G_{V}^{\prime} H_{W}^{\prime}-F_{V}^{\prime} G_{U}^{\prime}\right)+\operatorname{det} \boldsymbol{M}, \\
\Delta_{3}= & a_{3} \Delta_{2} .
\end{aligned}
$$


Since all coefficients (24) are positive the only determinant with possible non-positive value is $\Delta_{2}$. But taking the conditions (19) into account it is seen that for the given model parameters $\Delta_{2}>0$ $\left(k_{1}, k_{2} \neq 0\right)$.

Thus, the homogeneous steady-state solutions of (14) are stable for arbitrary $k_{1}, k_{2} \neq 0$. This means that the conditions for Turing bifurcation to occur are not satisfied for the given model parameters. That is, the system (13) is stable when diffusion effects are present if it was linearly stable in the case without diffusion (for $k_{1}, k_{2}=0$ ).

\section{Conclusions}

In this paper a two-dimensional mathematical model of carbon monoxide oxidation for the LangmuirHinshelwood mechanism is developed. The stability analysis of the model is conducted. By using linear stability analysis it is shown that for the given model parameters the system can lose stability only as the result of local bifurcation (the Hopf bifurcation). The conditions for instabilities caused by diffusion effects (the Turing bifurcation) to arise are not satisfied.

The spatio-temporal periodic chemical oscillations of $\mathrm{CO}$ and $\mathrm{O}$ surface coverages and the fraction of surface in the nonreconstructed $(1 \times 1)$-structure are obtained by means of numerical simulation.

[1] Sadeghi P., Dunphy K., Punckt C., Rotermund H. H. Inversion of pattern anisotropy during CO oxidation on $\mathrm{Pt}(110)$ correlated with appearance of subsurface oxygen. J. Phys. Chem. C. 116 (7), 4686-4691 (2012).

[2] Zaikin A. N., Zhabotinsky A.M. Concentration wave propagation in two-dimensional liquid-phase selfoscillating system. Nature. 225, 535-537 (1970).

[3] Rotermund H. H., EngelW., Kordesch M., ErtlG. Imaging of spatio-temporal pattern evolution during carbon monoxide oxidation on platinum. Nature. 343, 355-357 (1990).

[4] Jakubith S., Rotermund H. H., Engel W., von Oertzen A., Ertl G. Spatiotemporal concentration patterns in a surface reaction: Propagating and standing waves, rotating spirals, and turbulence. Phys. Rev. Lett. 65, 3013-3016 (1990).

[5] Nettesheim S., von Oertzen A., Rotermund H. H., Ertl G. Reaction diffusion patterns in the catalytic CO oxidation on Pt(110): Front propagation and spiral waves. J. Chem. Phys. 98, 9977-9985 (1993).

[6] Kim M., Bertram M., Pollmann M., von Oertzen A., Mikhailov A. S., Rotermund H. H., Ertl G. Controlling chemical turbulence by global delayed feedback: Pattern formation in catalytic CO oxidation on $\mathrm{Pt}(110)$. Science. 292, 1357-1360 (2001).

[7] Wolff J., Papathanasiou A. G., Kevrekidis I. G., Rotermund H. H., Ertl G. Spatiotemporal addressing of surface activity. Science. 294, 134-137 (2001).

[8] Slin'ko M. M., Jaeger N. I. Oscillating Heterogeneous Catalytic Systems (Studies in Surface Science and Catalysis). Eds. Amsterdam: Elsevier; Vol. 86 (1994).

[9] Baxter R. J., Hu P. Insight into why the Langmuir-Hinshelwood mechanism is generally preferred. J. Chem. Phys. 116 (11), 4379-4381 (2002).

[10] Wilf M., Dawson P. T. The adsorption and desorption of oxygen on the Pt(110) surface; a thermal desorption and LEED/AES study. Surf. Sci. 65, 399-418 (1977).

[11] Gomer R. Diffusion of adsorbates on metal surfaces. Rep. Prog. Phys. 53 (7), 917-1002 (1990).

[12] Kellogg G. L. Direct observations of the $(1 \times 2)$ surface reconstruction on the Pt(110) plane. Phys. Rev. Lett. 55, 2168-2171 (1985).

[13] Gritsch T., Coulman D., Behm R. J., ErtlG. Mechanism of the CO-induced $(1 \times 2)-(1 \times 1)$ structural transformation of Pt(110). Phys. Rev. Lett. 63, 1086-1089 (1989).

[14] Krischer K., Eiswirth M., ErtlG. Oscillatory CO oxidation on $\operatorname{Pt}(110)$ : Modeling of temporal selforganization. J. Chem. Phys. 96, 9161-9172 (1992).

[15] Bär M., Eiswirth M., Rotermund H. H., Ertl G. Solitary-wave phenomena in an excitable surface-reaction. Phys. Rev. Lett. 69 (6), 945-948 (1992). 
[16] Gasser R.P.H., Smith E. B. A surface mobility parameter for chemisorption. Chem. Phys. Lett. 1 (10), 457-458 (1967).

[17] Bertram M., Mikhailov A. S. Pattern formation on the edge of chaos: Mathematical modeling of CO oxidation on a Pt(110) surface under global delayed feedback. Phys. Rev. E. 67, 036207:1-11 (2003).

[18] Bzovska I. S., Mryglod I. M. Chemical oscillations in catalytic CO oxidation reaction. Condens. Matter Phys. 13 (3), 34801:1-5 (2010).

[19] Connors K. A. Chemical Kinetics: The Study of Reaction Rates in Solution. New York, VCH Publishers (1990).

[20] Suchorski Y. Private comunication.

[21] Korn G. A., Korn T. M. Mathematical handbook for scientists and engineers. Courier Corporation (2000).

[22] Kuznetsov Y. Elements of applied bifurcation theory. New York, Springer (1995).

[23] Bzovska I. S., Mryglod I. M. Surface patterns in catalytic carbon monoxide oxidation reaction. Ukr. Phys. J. 61 (2), 134-142 (2016).

[24] Hoyle R. Pattern Formation. New York, Cambridge University Press (2006).

\title{
Оксидація чадного газу на поверхні Pt-каталізатора: моделювання і стійкість
}

\author{
Рижа І., Мацелюх М. \\ Національний університет "Львівська політехніка" \\ вул. С. Бандери, 12, 79013, Львів, Україна
}

Досліджено двовимірну математичну модель оксидації чадного газу $(\mathrm{CO})$ для механізму Лангмюра-Гіншелвуда на поверхні платинового каталізатора $(\mathrm{Pt})$ з урахуванням перебудови поверхні каталізатора під впливом процесів адсорбції-десорбції. Проаналізовано стійкість розв'язків моделі. Виявлено просторово-часові періодичні хімічні коливання покриттів $\mathrm{CO}$, кисню $(\mathrm{O})$ та частки поверхні неперебудованої структури $(1 \times 1)$. Досліджено умови виникнення біфуркацій Хопфа та Тюрінга.

Ключові слова: каталітична реакчія окислення, реакчійно-дифузійна модель, біфуркачія Хопфа, бібуркачія Тюрінга.

2000 MSC: 37E99, 82D99, 82C21

УдК: 538.9 